\title{
Influence of shock controllability by dominant rats on subsequent attack and defensive behaviors toward colony intruders
}

\author{
JON L. WILLIAMS \\ Kenyon College, Gambier, Ohio
}

\begin{abstract}
Thirty colonies, each consisting of a female and two male adult albino rats, remained intact for an 8-week period. Naive conspecific intruders were then introduced into each colony for a 10min test for 5 consecutive days. Videotapes of the tests were scored for aggressive and defensive behaviors. In every colony, aggression was greatest for a single alpha male. The alpha rats were randomly given one of three treatments: wheel-turn escape training, inescapable yoked shock, or restraint without shock. The alpha rats were then returned to their colonies and an intruder test was given $26 \mathrm{~h}$ later. Significant decreases in aggressive responses and increases in defensive behaviors occurred in the alpha yoked group but not in the other alpha groups. The nonalpha colony partners of the alpha yoked rats showed the opposite changes following the treatment. A final intruder test $72 \mathrm{~h}$ later revealed that the deficits in aggression of the alpha yoked group were still present but that the behaviors of most of the other groups were beginning to return to their respective pretreatment levels. These findings were discussed in terms of the concept of learned helplessness and alternative theoretical explanations.
\end{abstract}

The finding that prior exposure to inescapable, as opposed to escapable, shock can have dramatic behavioral and physiological consequences has generated much research and theoretical interest (cf. Maier \& Seligman, 1976; Sklar \& Anisman, 1981). The presentation of inescapable shock has been shown to interfere with the ability of a variety of species to later learn a novel response to escape shock (e.g., Anisman, Suissa, \& Sklar, 1980; Maier, Albin, \& Testa, 1973; Overmier \& Seligman, 1967) or to learn an appetitive operant task (Rosselini, 1978). Transituational deficits resulting from inescapable shock have also been found in tests of nonassociative or unlearned behaviors, such as nonreinforced shuttlebox running (e.g., Maier, Coon, McDaniel, Jackson, \& Grau, 1979) and tail flicks to nociceptive stimuli (e.g., Jackson, Maier, \& Coon, 1979).

Of particular relevance to the present study are findings that indicate that exposure to inescapable shock greatly affects unlearned agonistic behaviors. Numerous studies have demonstrated that inescapable shock markedly suppresses subsequent shock-elicited aggression (e.g., Anderson, Crowell, Wikoff, \& Lupo, 1980; Maier, Anderson, \& Lieberman, 1972; Payne, Anderson, \& Murcurio, 1970; Powell \& Creer, 1969). However, the notion

This research was partially supported by a faculty development grant to Kenyon College from the Mellon Foundation. Portions of the results were presented at the 1981 meetings of the Rocky Mountain Psychological Association and the Psychonomics Society. Reprints may be obtained from the author, Department of Psychology, Kenyon College, Gambier, Ohio 43022. that shock-elicited aggression reflects attack or aggressive tendencies has been vehemently challenged on a number of grounds by Blanchard and his colleagues (R. J. Blanchard \& D. C. Blanchard, 1977; R. J. Blanchard, D. C. Blanchard, \& L. K. Takahashi, 1978; L. K. Takahashi \& R. J. Blanchard, 1978). First, the specific behaviors typically seen during shock-elictied aggression are very similar to those shown by colony intruder rats under attack and do not resemble the fighting pattern of a dominant male resident in an established colony. Second, the forelimb movements that have typically been interpreted as "striking" during shock-elicited aggression have been shown to partially represent uncontrolled movements elicited by the footshock when the forelimbs are suspended or when the rat is engaged in defensive boxing. Third, the majority of the bites and wounds made by rats during elicited aggression are directed at the conspecific's head region. This target area is far more typical of the defensive behavior of an intruder than the attack fighting of a dominant male in a colony setting.

In addition to being a questionable measure of attack behavior, elicited aggression is not a suitable task for assessing the true breadth of the helplessness effect because it involves electric shock during the treatment as well as during the test phase. The reduction in elicited aggression following inescapable shock could therefore be due to a variety of mechanisms (e.g., learned response-reinforcer independence, neurochemical depletions, learned competing responses, shock analgesia). Rapaport and Maier (1978) report what appears to be a more convincing 
expample of the widespread effect of inescapable shock on agonistic behavior that did not involve exposure to shock during testing. In that experiment, groups of rats were given the typical triadic treatment of escapable, yoked inescapable, or no shock and then tested for dominance in a series of round-robin food-competition tests. The rats in the inescapable shock group were the only ones to show a decrease in dominance, and a follow-up experiment indicated that this finding could not be attributed to reduced hunger. However, whether aggression is being measured in this type of food-competition situation is somewhat doubtful. None of the published competitiontest studies has reported the occurrence of aggressive or attack behaviors in the tube or at the intersection of two alleys, where supposedly vigorous agonistic behaviors should occur. A few studies (e.g., Barr, Gibbons, \& Moyer, 1975; Miczek \& Barry, 1974) have reported observing agonistic behaviors in the end boxes of competition tubes, but these responses were much less frequent and intense than the aggressive colony behaviors described by Blanchard and his colleagues. Furthermore, end-box fighting seems to be functionally different from the factors that determine "victory" in the tube area. Grossman (1972), for example, reports that dominant rats ( $100 \%$ victors in previous tube tests) won only $57 \%$ of the mildly aggressive encounters that took place in the end boxes.

The present experiment was designed to overcome some of the conceptual and methodological problems of previous studies by using a colony-intruder task as a way of assessing changes in dominance as a function of the degree of controllability of prior electric shock. More specifically, this experiment involved the following phases: (1) determining the dominant male rat in separate colonies by introducing naive intruders and scoring attack and defensive behaviors from videotaped recordings, (2) giving the dominant rats of each colony escape training, yoked shock, or restraint without shock, and (3) testing for changes in dominance (i.e., attack and defense) when the dominant rats have been returned to their original colonies and confronted by a naive intruder $26 \mathrm{~h}$ and $98 \mathrm{~h}$ after triadic shock treatment. Thus, in contrast with previous studies, the influence of the degree of control of shock on later aggression involved videotaped observations of species-specific attack and defensive behaviors with an intruder in a nonshock colony situation in which vigorous aggression is known to occur.

\section{METHOD}

\section{Subjects}

One hundred and eighty male and 30 female albino Holtzman rats, which had been obtained from the supplier at 35 days of age, were used as subjects. Upon arrival in the laboratory, they were singly housed in rack cages under a standard schedule with food and water freely available. At 75 days of age, 60 male and 30 female rats were randomly assigned to 30 colony cages such that 2 males and 1 female resided in each colony. The colony animals, as well as the remaining 120 male rats, which were housed in isolated cages and later used as intruders, continued to be maintained with free access to food and water for an additional 8-week period. Previous studies (e.g., R. J. Blanchard \& D. C. Blanchard, 1977) and pilot research by the author have indicated that male dominance and aggression are facilitated by having mixed-sex colonies remain intact for an extended period. Throughout the entire experiment, newborn pups were removed from the colonies within $10 \mathrm{~h}$ after birth.

\section{Apparatus}

The 30 colonies were each housed in $20 \times 50 \times 40 \mathrm{~cm}$ polypropylene tanks with stainless steel wire tops. Food and water were freely available in these tanks. The floors of the colony cages were covered with ground corn cob mesh as bedding material, which was changed every 3 weeks but not immediately prior to or during the colony-intruder test phase.

Observations and recordings, by means of a Panasonic color videotape recorder with slow motion and frame-by-frame options, were made through the wire covers of the colony cages after the food and water bottles had been removed. The colony animals and intruders were marked with different colors of Fuschan Basic dye to facilitate identification and later analysis. A multichannel event recorder, operated by a trained observer, was used to chart the frequency, duration, and sequence of specific attack and defensive behavior that occurred during the colony-intruder tests.

Shock and restraint conditions were given in three wheel-turn boxes measuring $15.5 \times 12.0 \times 17.0 \mathrm{~cm}$. The side, front, and rear walls, as well as the top and floor of each chamber, were made of Plexiglas. A 6.4-cm-diam grooved Plexiglas wheel was located on the front wall and extended $1.5 \mathrm{~cm}$ into the chamber. The force required to move the wheel a quarter turn was approximately $30 \mathrm{~g}$. The rat's tail extended through a hole in the rear of each apparatus and was taped to a Plexiglas rod. In two of the three chambers, unscrambled shocks were delivered to the rat's tail via fixed electrodes from separate constant-current Lafayette $\mathbf{8 2 4 0 0}$ shock sources, which were continuously calibrated. Each chamber was housed in a sound-attenuating box equipped with a whitenoise speaker, a houselight, and a ventilating fan. All treatment contingencies were electronically controlled, and the wheel-turn latencies in the chamber used for escape training were automatically recorded via an electric printout timer.

\section{Procedure}

After the colonies had been established for an 8-week period, 30 males in the isolated rack cages were individually introduced into separate colonies for a 10-min period once each evening $(7: 00 \mathrm{p} . \mathrm{m}$.12:00 p.m.) for 4 consecutive days. These four sessions were given as sparring contests, which had been shown to be important in increasing aggression and establishing clear dominance in one of the male residents of a colony (R. J. Blanchard, L. K. Takahashi, \& D. C. Blanchard, 1977).

A day after the last sparring contest, another naive male intruder from an isolated cage was introduced for $10 \mathrm{~min}$ into each colony in a 24 -h pretreatment test. Videotape recordings were made of this session and of all subsequent 10-min colony-intruder tests, and two trained observers later scored the tapes via multichannel event recorder. Because the focus of this study was on male dominance competition within the colonies, records were made only of the attack and defensive behaviors exhibited by the two male residents of each colony when they interacted with the intruder.

The four types of attack or aggressive behaviors that were scored were: (1) number and duration of lateral attacks-observed resident male moved laterally to and within $5 \mathrm{~cm}$ of the intruder, typically with arched back and head lowered, (2) number of bites and their locations, (3) latency to piloerection-time until clear 
erection of back hairs on the observed animal, (4) number and duration of on-top-of instances-observed rat stood directly over intruder, which was lying on its back. The three types of defensive behaviors scored for the male residents were: (1) number and durations of fleeing instances-observed rat pursued by intruder, typically after an aggressive encounter, (2) number and durations of defensive boxing instances-observed rat in an upright boxing posture with forepaws off the floor and oriented toward and within $5 \mathrm{~cm}$ of the intruder, (3) number and durations of on-theback instances-observed resident lying on its back, with the intruder having assumed an on-top-of position. More complete definitions and descriptions of these attack and defensive behaviors may be found in previous studies (see R. J. Blanchard \& D. C. Blanchard, 1977). Agreement between the two trained observers, who independently scored the videotapes of the colonyintruder tests, was greater than $90 \%$ for each of the monitored behaviors. Since the scoring procedure was found to be reliable, all subsequent tests were scored by a single observer who was blind to the experimental groups to which the subjects were later assigned.

From the results of the 24-h pretreatment test, it was obvious which of the two male residents in each colony was dominant. Consistent with other studies (e.g., R. J. Blanchard \& D. C. Blanchard, 1977; R. J. Blanchard et al., 1977), the dominant, or alpha, male resident showed far more aggressive behaviors and fewer defensive behaviors than did its nonalpha partner.

Following the 24-h pretreatment colony-intruder test, the alpha residents of each colony were randomly assigned to one of three treatments: wheel-turn escape training, inescapable yoked shock, or restraint without shock. The alpha animals were run in triplets of escape (AE), yoked (AY), and restrained (AR) subjects $24 \mathrm{~h}$ after the pretreatment colony-intruder test. The $A E$ rats received one shock-escape training session in the wheel-turn box. The session contained 80 trials presented on a variable time schedule, with a mean interval of $60 \mathrm{sec}$ and a range of 30-120 sec. Shock terminated when the rat had completed a one-quarter turn of the wheel beyond $.8 \mathrm{sec}$ following shock onset. Wheel turns during the first $.8 \mathrm{sec}$ of shock were considered to be unlearned shockelicited responses, which would not function as an effective coping behavior against a helplessness effect (Maier \& Jackson, 1977). Therefore, such responses were programmed to have no consequence. Shock presentations terminated after $30 \mathrm{sec}$ if an escape response had not occurred. The shock intensity for all $A E$ and $A Y$ rats began at $.8 \mathrm{~mA}$ and was increased to $1.0 \mathrm{~mA}$ on Trial 20 , to $1.3 \mathrm{~mA}$ on Trial 40 , and to $1.6 \mathrm{~mA}$ on Trial 60 . This was done because previous studies (e.g., Maier \& Jackson, 1977) and pilot research by the author had revealed a deterioration of performance when the intensity remained constant over trials.

The AY subjects received the same number, duration, and intensity of shocks as had their AE partners. Shock began simultaneously for both subjects and terminated whenever the $A E$ rat made the appropriate wheel-turn response. Subjects in Group AR were restrained in the wheel-turn box for an identical period of time but were not shocked. Immediately following this triadic treatment, each of the three alpha animals was returned to its original colony cage with the female rat and its male nonalpha partner (NE, NY, or NR, for the respective groups).

To determine the effects of the triadic treatment on the behavior of the two male residents of each colony, a 26-h posttreatment colony-intruder test was given according to the same procedure as that used in the 24-h pretreatment test. To test for possible longterm effects, a final 98-h posttreatment colony-intruder test was given $72 \mathrm{~h}$ following the previous test. The intruder rats for both of these tests were the remaining 60 naive males residing in the isolated cages. Thus, all test intruders were naive and approximately the same age and weight as the two male residents of each colony.

\section{RESULTS}

Figure 1 presents the number of instances and cumulative durations of the aggressive and defensive behaviors for the three groups of alpha rats and their respective nonalpha colony partners during the colony-intruder tests. The alpha rats in each group made many more aggressive and far fewer defensive responses than the nonalpha subjects during the pretreatment test. Likewise, the alpha rats showed longer cumulative durations of engaging in aggressive behaviors and shorter durations of defensive responses than the nonalpha rats. Newman-Keuls tests, following a series of three-way (position $\times$ group $x$ test) ANOVAs, revealed that the differences in all of the response measures during pretreatment test between the alpha and nonalpha groups were significant (ps $<.01)$.

Attack or aggressive behaviors in each colony were made by a single male resident (i.e., the alpha rat) during the pretreatment test. Over $90 \%$ of the alpha rat's attacks, in each of the colonies, were made against the intruder. The general pattern of responses was remarkably consistent across the colonies. The first reactions of the alpha rat to the presence of the intruder were approach and investigatory sniffing. Within 20 to $40 \mathrm{sec}$ after such sniffing, piloerection of the hairs on the alpha rat's back typically occurred. Active aggressive responses were then initiated by the alpha rat's making a series of lateral attacks. These lateral attacks consisted of a sideways movement of the alpha animal's entire body against the intruder and with the snout oriented toward the intruder's back. When the alpha rat made these attacks, the intruder engaged in defensive boxing, with its forepaws off the floor and directed toward the attacking rat. These forelimb-extension movements were not strikes at the attacker but, rather, appeared to be defensive behaviors that were rarely made by the dominant resident. When the alpha rat lunged or attempted to bite the intruder, the intruder typically pivoted so as to constantly be facing the attacker. Only when the alpha rat made a very rapid dart forward from the lateral attack position did bites occur.

During pretreatment testing, lateral attacks on defending intruders resulted in an average of $73.22 \%$ of the total bites made by the dominant rat in each of the colonies. The alpha rats made $82.21 \%$ of their bites on the back of the intruder. Far fewer bites were made on the other locations of the intruder's body, with $5.26 \%$ on the head, $10.42 \%$ on the limbs, and only $2.11 \%$ on the thorax and abdomen. During only two colony-intruder tests did an intruder bite an alpha resident, and on eight occasions the intruder bit the nondominant rat. In contrast with the alpha rat's target locations, the intruders made $76.21 \%$ of all their bites on the head and only $10.51 \%$ on the back of either of the two male residents.

After biting the intruder, the dominant rat frequently stood on top of the intruder for 5-15 sec. Then it would leave the intruder for a short period and later return to begin a new bout with a series of lateral attacks. Another sequence of behaviors, 


\section{AGGRESSIVE BEHAVIORS}
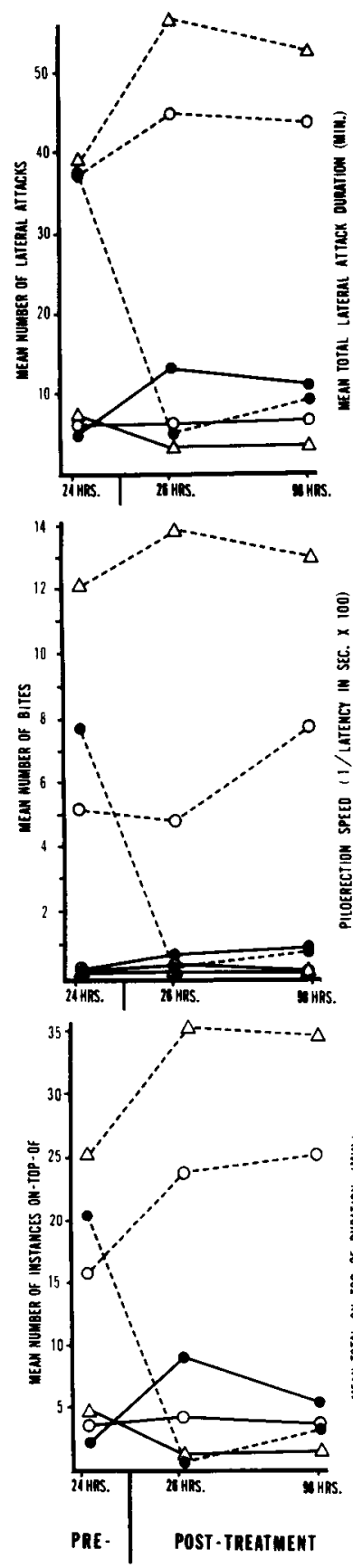
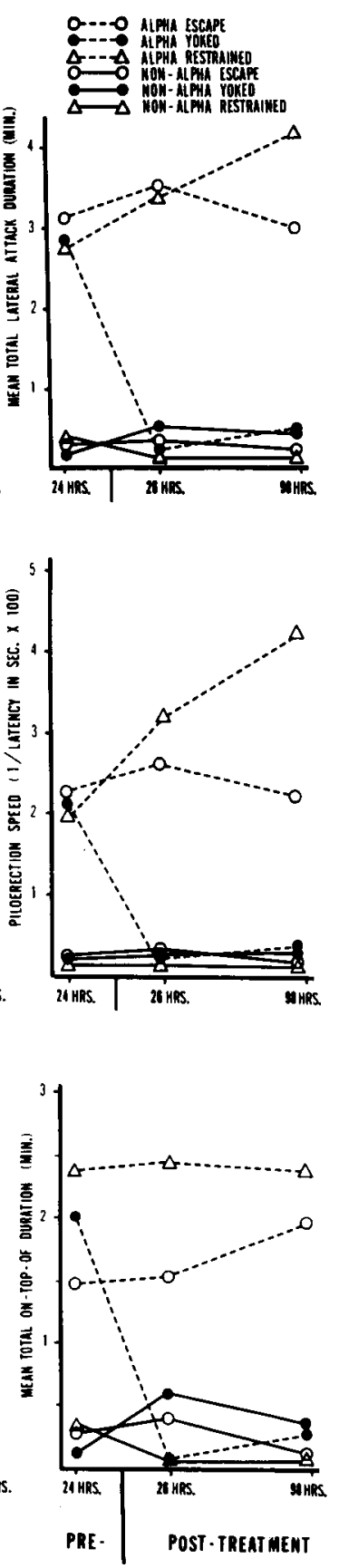

DEFEMSIVE BEHAVIORS
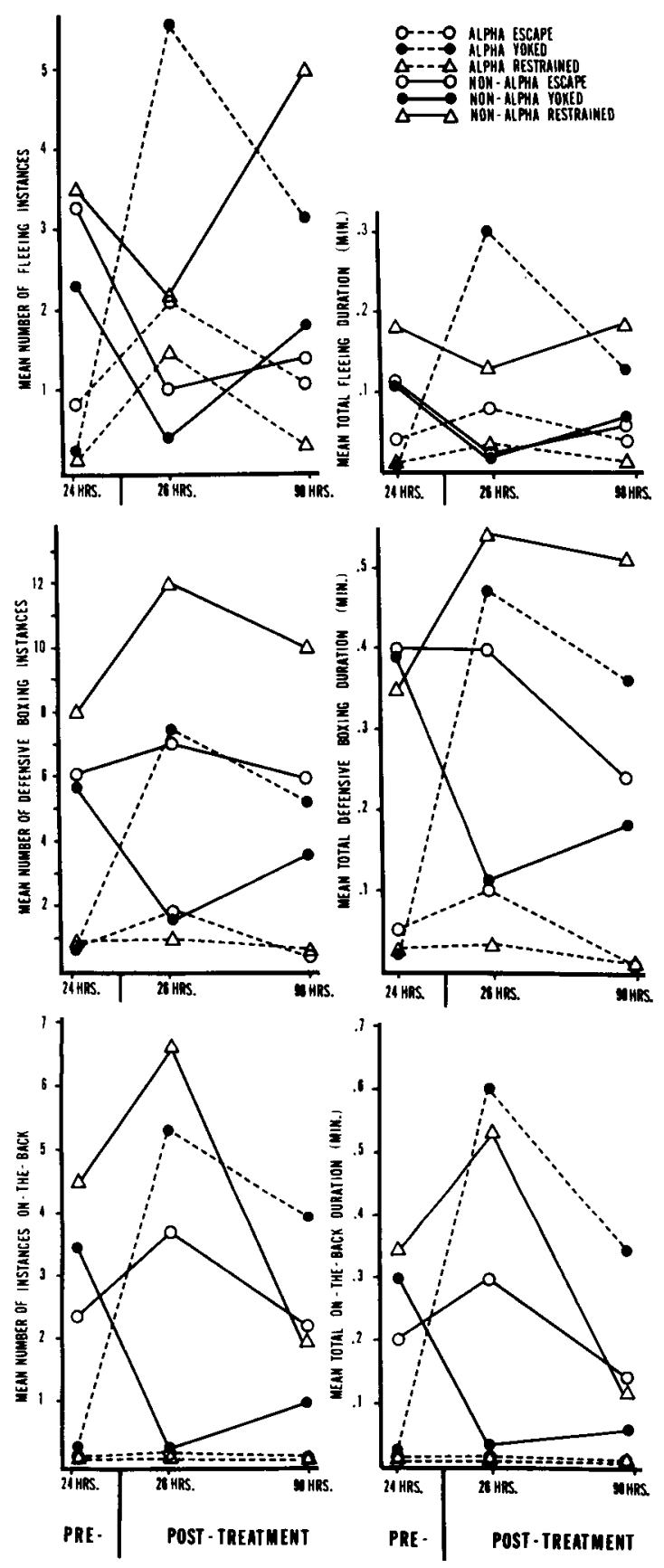

Figure 1. Mean number of instances and cumulative durations (in seconds) of aggressive (left half) and defensive (right half) behaviors for the alpha rats and their respective nonalpha colony partners during the pretreatment and the two posttreatment colony-intruder tests. Groups Alpha Escape (AE), Alpha Yoked (AY), and Alpha Restrained (AR) were the male rats during the pretreatment test. Groups Nonalpha Escape (NE), Nonalpha Yoked (NY), and Nonalpha Restrained (NR) were the nondominant male partners of the alpha rats, but these animals did not directly experience one of the three shock treatments.

which often occurred after biting by the alpha rat, was initiated by the fleeing of the intruder. This invariably led to chasing and biting by the alpha attacker. The intruder usually responded by twisting over onto its back, and the alpha rat remained on top of the defending animal for 5-15 sec.
The nonalpha rat often joined the dominant rat's attack on the intruder for a short period during pretreatment testing. However, the nonalpha animal typically reverted to making defensive behaviors in response to the intense fighting by the alpha rat against the intruder. These defensive behaviors con- 
sisted of infrequent and brief instances of fleeing and lying on the back and relatively more occurrences of defensive boxing. The nonalpha rats showed very few instances of aggressive behaviors and rarely bit intruders during the pretreatment test.

All 10 of the alpha rats in Group AE learned the wheel-turn escape response during the triadic shock treatment phase. Their mean latencies decreased significantly over eight successive blocks of 10 acquisition trials $[F(7,63)=7.12, p<.01]$, with a mean of $10.61 \mathrm{sec}$ on the first block and a mean of $2.18 \mathrm{sec}$ on the final block of trials.

Intruder tests: Aggressive behaviors. The left half of Figure 1 presents the six measures of aggression observed during each of the intruder tests. The changes in these responses across tests and the differences between groups were examined by means of a series of between-within ANOVAs, with the between variables being two positions (alpha and nonalpha) and three groups (escape, yoked, and restrained) and the within variables being a successive pair of intruder tests (i.e., either the pretreatment and the 26-h posttreatment tests of separate ANOVAs using the data from the $26-\mathrm{h}$ and the 98 -h posttreatment tests). The complete findings of these analyses with regard to overall main effects and interactions for each of the aggressive response measures are presented in Table 1 at the end of the results section. All main effects and interactions found to be statistically significant at the .05 level were further analyzed by a series of Newman-Keuls tests to determine whether the differences either within or between groups were significant. Only the findings for which the Newman-Keuls tests are significant (at either the .05 or .01 level) and that are of theoretical importance are described.

As can be seen from Figure 1, the alpha rats in Group AY showed a striking $(p<.01)$ decline in all of the aggressive behaviors from the pretreatment to the 26-h posttreatment test. A minimal display of aggression was again observed for these rats during the final 98-h posttreatment test. In contrast, there was no decrease in aggressive responses for Groups $\mathrm{AE}$ and AR following the experimental treatment, with the former group showing an increase in the number of lateral attacks $(p<.05)$ and on-top-of responses $(p<.01)$ and the latter group making more lateral attacks $(p<.01)$ of a longer total duration $(p<.05)$, showing faster piloerection speed $(p<.05)$, and more instances of on-top-of responses $(p<.01)$. Group AR continued to show an increase in lateral attack duration $(p<.05)$ and piloerection speed $(p<.05)$ on the final 98-h test.

With respect to the nonalpha animals, Group NY was the only group that revealed an increase in the number of lateral attacks $(p<.05)$, on-top-of responses $(p<.05)$, and the total duration of on-topof responses $(p<.05)$ between the pretreatment and posttreatment tests. These increases in aggressive behaviors subsided to some extent by the 98 -h test. The remaining nonalpha groups showed relatively little aggression on all three tests.

As mentioned before, the three alpha groups differed significantly (ps $<.01$ ) from the three nonalpha groups with regard to all six measures of aggression during the initial pretreatment test. However, AY rats made significantly fewer lateral attacks $(p<.05)$ and on-top-of responses $(p<.05)$ than their nondominant NY colony partners during the 26-h test. This obvious reversal in aggression between the AY and the NY groups was somewhat transitory, and the response measures for these groups were virtually indistinguishable by the final 98 -h test.

Intruder tests: Defensive behaviors. The right half of Figure 1 presents the number of instances and total durations of the three defensive behaviors occurring during the intruder tests. As with the aggression results, these data were examined by means of a series of between-within ANOVAs for the pre- and posttreatment tests and the two posttreatment tests, respectively. The complete presentation of the outcomes of these analyses, in terms of overall main effects and interactions, is shown in Table 2. All significant effects were further examined by a series of Newman-Keuls tests to determine the existence of significant differences across tests and between groups. Compared with the results of the aggressive responses, defensive behaviors occurred less frequently and relatively large variability was found within subjects across the two successive pairs of intruder tests. Only the significant findings of theoretical interest are described here.

As revealed in Figure 1, the alpha rats in Group AY showed an increase (ps $<.01$ ) in the number of instances and the total durations of all three defensive behaviors following the experimental treatment involving inescapable shock. This increase in defensive behavior is in marked contrast with the large decrement in aggression that was previously noted for these rats during the 26-h test (left half of Figure 1). However, unlike the change in their aggressive responses, the increase in defensive behavior seen during the first posttreatment test was considerably attenuated by the final 98 -h test with respect to all six response measures. This was particularly the case for the number of fleeing instances $(p<.05)$, durations of fleeing instances $(p<.01)$, and on-theback durations $(p<.05)$. The remaining two alpha groups showed a similar trend in defensive responding across tests in terms of fleeing instances, but none of these changes was statistically significant. The AE and AR groups also engaged in far fewer defensive behaviors (ps < .01) for shorter total durations (ps $<$ .01 ) than the AY rats on the final 98-h test.

For the nonalpha groups, the yoked rats in Group NY showed the opposite changes in responses 
from pre-to posttreatment testing relative to their dominant colony partners (i.e., Group AY). After the treatment, the NY rats had fewer instances (ps $<.05$ ). and shorter total durations (ps $<.05$ ) of all three defensive behaviors. This contrasts with the increment in aggression (i.e., lateral attack and ontop-of responses) that was previously noted for this group during the 26-h test (left half of Figure 1). The decrease in defensive behavior by NY rats after the experimental treatment recovered to some degree by the final 98 -h test, but none of the increases in these response measures was found to be statistically significant. For Groups NE and NR, there were similar reductions (ps $<.05)$ after the experimental treatment with respect to the number of instances and total durations of fleeing instances, reductions which were later recovered by the final intruder test. However, in terms of most of the remaining four response measures, these two groups of nonalpha rats displayed an increase in defensive behaviors after the treatment phase.

As mentioned earlier, all three groups of alpha rats displayed far fewer instances (ps $<.01)$ and shorter total durations ( $p s<.01$ ) of defensive behavior than the three groups of nonalpha rats during the pretreatment test. With respect to the $26-\mathrm{h}$ posttreatment test, however, Group AY showed significantly more defensive behavior than Group NY for all six response measures (ps $<.01$ ). The reversal in defensive behavior for these two yoked groups during the 26-h test was still found to be significant (ps $<.05$ ) by the 98 -h test for defensive boxing durations, onthe-back instances, and on-the-back durations. The lack of significance for the other three measures was due to the fact that the responses had partially re- turned to their respective pretreatment levels by the final intruder test.

\section{ANOVA Results}

The results of the ANOVAs conducted on each aggression measure for the pretreatment vs. 26-h posttreatment tests and the $26-\mathrm{h}$ vs. 98 -h posttreatment tests, respectively, are shown in Table 1 . Table 2 presents the results of the ANOVAs performed on the various measures of defensive behavior with respect to the same two pairs of intruder tests. As noted before, the significant (ps $<.05$ ) main effects and interactions obtained with these analyses legitimized the subsequent use of Newman-Keuls tests to identify more precisely the major findings that have been previously described.

\section{DISCUSSION}

If small, mixed-sex colonies of albino rats remain intact for an extended period of time and strange male rats of the same strain and age are occasionally introduced into the colony, a single male resident (i.e., the alpha rat) will aggressively attack these intruders. While a nonalpha resident may occasionally join the alpha rat's attack on the intruder, this animal shows much less aggressive and more defensive behavior than its dominant colony partner. These findings, as well as the topographies and patterns of aggressive and defensive behaviors that occurred in this experiment, are consistent with the observations reported by Blanchard and his colleagues (e.g., R. J. Blanchard \& D. C. Blanchard, 1977; R. J. Blanchard et al., 1977).

The major finding of this experiment, however,

Table 1

Mean-Square Values of Overall Main Effects and Interactions for Aggressive Behaviors

\begin{tabular}{|c|c|c|c|c|c|c|c|}
\hline Source & $\mathrm{df}$ & $\begin{array}{l}\text { Lateral } \\
\text { Attacks }\end{array}$ & $\begin{array}{l}\text { Lateral Attack } \\
\text { Duration }\end{array}$ & Bites & $\begin{array}{l}\text { Piloerection } \\
\text { Speed }\end{array}$ & $\begin{array}{l}\text { On-Top-of } \\
\text { Responses }\end{array}$ & $\begin{array}{c}\text { On-Top-of } \\
\text { Duration }\end{array}$ \\
\hline & \multicolumn{7}{|c|}{ ANOVAs for the 24-h Pretreatment vs. 26-h Posttreatment Tests } \\
\hline (1) Position & 1 & $26347.55 \dagger$ & $162.25 \dagger$ & $1462.78 \dagger$ & $102.53 \dagger$ & $7888.89 \dagger$ & $57.00 \dagger$ \\
\hline (2) Group & 2 & $1319.54 \dagger$ & $7.86 t$ & $237.06 \dagger$ & $6.24^{*}$ & $736.37 \dagger$ & $2.04^{*}$ \\
\hline (3) Position by Group & 2 & $2539.83+$ & $10.33 \dagger$ & $263.42 \dagger$ & $7.53 \dagger$ & $1269.88 \dagger$ & $7.00 \dagger$ \\
\hline Error-Sources 1-3 & 54 & 83.41 & .59 & 25.60 & 1.29 & 64.20 & .46 \\
\hline (4) Test & 1 & 6.05 & .38 & 25.06 & .33 & 12.19 & 1.00 \\
\hline (5) Position by Test & 1 & 92.81 & $2.90 \dagger$ & 32.98 & .27 & 28.96 & $6.01 \dagger$ \\
\hline (6) Group by Test & 2 & $992.15+$ & $6.28 \dagger$ & $54.47^{*}$ & $5.67+$ & $341.99 \dagger$ & $2.50 \dagger$ \\
\hline (7) Position by Group by Test & 2 & $2617.84 \dagger$ & $9.67 \dagger$ & $67.01 \dagger$ & $6.75 \dagger$ & $1088.75 \dagger$ & $4.51 \dagger$ \\
\hline \multirow[t]{2}{*}{ Error-Sources 4-7 } & 54 & 50.44 & .29 & 13.19 & .98 & 30.48 & .31 \\
\hline & \multicolumn{7}{|c|}{ ANOVAs for the $26-\mathrm{h}$ vs. $98-\mathrm{h}$ Posttreatment Tests } \\
\hline (1) Position & 1 & $23519.75 \dagger$ & $142.13 \dagger$ & $1241.99 \dagger$ & $109.59 \dagger$ & $8083.95 \dagger$ & $39.84 \uparrow$ \\
\hline (2) Group & 2 & $4214.27 \dagger$ & $27.56 \dagger$ & $393.01 \dagger$ & $29.01 \dagger$ & $1972.11 \dagger$ & $8.28 \dagger$ \\
\hline (3) Position by Group & 2 & $8607.30 \dagger$ & $40.23 \dagger$ & $476.83 \dagger$ & $32.55 \dagger$ & $3910.69 \dagger$ & $19.08 \dagger$ \\
\hline Error-Sources 1-3 & $5 \overline{4}$ & 135.42 & .69 & 34.78 & 1.50 & 79.81 & .51 \\
\hline (4) Test & 1 & 14.03 & .12 & 6.07 & .37 & 16.54 & .11 \\
\hline (5) Position by Test & 1 & 3.51 & .59 & 6.97 & 1.13 & 59.63 & .69 \\
\hline (6) Group by Test & 2 & 15.34 & $1.18+$ & 6.97 & 1.37 & 18.73 & .16 \\
\hline (7) Position by Group by Test & 2 & 77.14 & $.93^{*}$ & 9.97 & .96 & 40.58 & .36 \\
\hline Error-Sources 4-7 & 54 & 43.83 & .21 & 6.01 & .63 & 31.22 & .20 \\
\hline
\end{tabular}

${ }^{*} p<.05 . \quad t_{p}<.01$. 
Table 2

Mean-Square Values of Overall Main Effects and Interactions for Defensive Behaviors

\begin{tabular}{|c|c|c|c|c|c|c|c|}
\hline Source & df & $\begin{array}{c}\text { Fleeing } \\
\text { Responses }\end{array}$ & $\begin{array}{l}\text { Duration } \\
\text { of Fleeing }\end{array}$ & $\begin{array}{c}\text { Defensive } \\
\text { Boxing }\end{array}$ & $\begin{array}{l}\text { Duration } \\
\text { of Boxing }\end{array}$ & $\begin{array}{c}\text { On-the-Back } \\
\text { Responses }\end{array}$ & $\begin{array}{c}\text { On-the-Back } \\
\text { Duration }\end{array}$ \\
\hline & \multicolumn{7}{|c|}{ ANOVAs for the 24-h Pretreatment vs. $26-\mathrm{h}$ Posttreatment Tests } \\
\hline (1) Position & 1 & 3.98 & .01 & $644.03 t$ & $1.70 \dagger$ & $189.99 \dagger$ & $.99 \dagger$ \\
\hline (2) Group & 2 & 1.99 & .02 & 28.31 & .01 & 16.49 & .13 \\
\hline (3) Position by Group & 2 & $35.50 \dagger$ & $.12 \dagger$ & $219.53 \dagger$ & $.50 \dagger$ & $103.99 \dagger$ & $.92 \dagger$ \\
\hline Error-Sources $1-3$ & $5 \overline{4}$ & 4.85 & .01 & 13.61 & .04 & 7.89 & .09 \\
\hline (4) Test & 1 & 8.01 & $.04^{*}$ & 63.90 & .10 & 26.94 & .31 \\
\hline (5) Position by Test & 1 & $161.99 \dagger$ & $.56 \dagger$ & 47.93 & .03 & 21.90 & .27 \\
\hline (6) Group by Test & 2 & $14.99^{*}$ & $.11 \dagger$ & 2.52 & .05 & 2.12 & .04 \\
\hline (7) Position by Group by Test & 2 & $17.48 \dagger$ & $.13 \dagger$ & $146.93 \dagger$ & $.99 \dagger$ & $83.95 \dagger$ & $.85 \dagger$ \\
\hline \multirow[t]{2}{*}{ Error-Sources 4-7 } & 54 & 3.19 & .01 & 21.02 & .07 & 10.09 & .001 \\
\hline & \multicolumn{7}{|c|}{ ANOVAs for the 26-h vs. 98-h Posttreatment Tests } \\
\hline (1) Position & 1 & 4.99 & .01 & $455.72 \dagger$ & $.77 \dagger$ & 30.95 & .03 \\
\hline (2) Group & 2 & 20.04 & $.04^{*}$ & 40.95 & .11 & 12.45 & .22 \\
\hline (3) Position by Group & 2 & $94.47 \dagger$ & $.15 \dagger$ & $504.77 \dagger$ & $1.58 \dagger$ & $192.54 \dagger$ & $1.73 \dagger$ \\
\hline Error-Sources 1-3 & 54 & 7.13 & .01 & 23.81 & .08 & 12.43 & .12 \\
\hline (4) Test & 1 & .99 & .01 & 16.96 & .07 & $40.01 *$ & $.52 \dagger$ \\
\hline (5) Position by Test & 1 & $76.97 \dagger$ & $.15 \dagger$ & 8.90 & .02 & 11.97 & .06 \\
\hline (6) Group by Test & 2 & 5.45 & .03 & 3.96 & .04 & 10.97 & .04 \\
\hline (7) Position by Group by Test & 2 & 5.45 & .01 & 18.93 & .04 & $30.54 \dagger$ & $.32 *$ \\
\hline Error-Sources 4-7 & 54 & 5.80 & .02 & 14.13 & .05 & 7.17 & .07 \\
\hline
\end{tabular}

${ }^{*} p<.05 . \quad t_{p}<.01$.

was that inescapable shock to alpha rats virtually eliminated all forms of aggression for as long as $98 \mathrm{~h}$ after the shock treatment. These animals also showed an initial increase in defensive behaviors, an increase that gradually declined. In contrast, there was no decrease in aggressive responses for alpha rats that had escapable shock or were simply restrained without shock for the same period. In fact, the latter group of animals showed significant increases in the occurrence of several aggressive behaviors (i.e., lateral attack, piloerection, and number of on-top-of responses). Furthermore, the nonalpha partners of the inescapably shocked alpha rats became somewhat more aggressive and less defensive in the short-term 26-h posttreatment test, presumably in response to the decline in dominance of their alpha partners. A similar reversal of dominance status in competition testing after alpha rats had received septal lesions was reported by Costanzo, Enloe, and Hothersall (1977), and such lesions have also been shown to produce reductions in attack by alpha rats on intruders (e.g., D. C. Blanchard, R. J. Blanchard, L. K. Takahashi, \& T. Takahashi, 1977).

It is not clear what mechanism or process can best explain the fact that inescapable shock produces a striking, long-term reduction in aggression and a short-term increment in defensive behaviors in dominant colony rats. Bracewell and Black (1974) and Glazer and Weiss (1976a, 1976b) have argued that a motor response of remaining inactive is acquired during exposure to inescapable shock and that this reduced movement competes with the acquisition and performance of subsequent responses that are motivated by shock. More recently, Anderson, Crowell, Cunningham, and Lupo (1979) and
Anderson et al. (1980) have specifically manipulated the amount of activity during exposure to inescapable shock and have shown that inactivity during shock, rather than the uncontrollability of shock, may be the critical determinant that interferes with subsequent shuttlebox escape learning and shockelicited aggression, respectively. The proponents of all these competing-response views assume that the actual presence of shock in most helplessness studies mediates the transfer of inactivity from the inescapable shock to the testing situations. However, there was no shock or any other aversive stimulus used in the colony-intruder tests in the present study. Thus, if any forms of inactivity or competing responses had been acquired during the inescapable shock exposure, it is difficult to see how they could have transferred to the home colony setting and produced differential effects on aggressive and defensive behaviors.

According to the learned helplessness hypothesis (Maier \& Seligman, 1976), deficits in learning and performance following inescapable shock result exclusively from the acquisition of a cognitive state in which the organism perceives its responses and the presentations of reinforcers as independent events. This learned cognitive state is further assumed to decrease the animal's ability to perceive responsereinforcer contingencies in subsequent tasks involving novel responses and situations. This prediction from the theory clearly does not account for the present findings, because the agonistic behaviors that were observed during colony-intruder tests were unlearned, species-specific responses. However, Maier and Seligman have also postulated that exposure to inescapable shock produces an emotional deficit or 
passivity. This symptom of inescapable shock appears to be consistent with the reduction in aggression, and possibly the increment in defense, that was observed in this study for the alpha rats given inescapable shock. The fact that a disruption in agonistic behavior was seen for only the AY rats, and not the AE or AR subjects, also agrees with the learned helplessness hypothesis. However, this position would predict that prior victories over intruders in the sparring and pretreatment sessions should "immunize" the alpha rats from the effects of uncontrollable shock. Perhaps immunization did not occur in this study, since fighting intruders involved unlearned, reflexive behaviors (Maier \& Jackson, 1977), which were not motivated by shock. Furthermore, Williams and Maier (1977) have shown that immunization with escape training preceding inescapable shock only partially reduces the so-called helplessness effect. Perhaps this is also the case with prior agonistic victories.

One of the major weaknesses of the learned helplessness theory is that its proponents have not as yet provided a specific behavioral or physiological mechanism that explains precisely how inescapable shock produces emotional deficit and passivity. Recently, Jackson et al. (1979) and MacLennan, Jackson, and Maier (1980) have demonstrated that inescapable, but not escapable, shock has an analgesic effect when subjects are reexposed to aversive stimuli in a later test situation. The results of these studies also suggest that many of the previously reported findings that support the helplessness theory (e.g., retarded learning and slower running in the shuttlebox, reduced fighting in shock-elicited aggression) might readily be mediated by an analgesic reaction that can be conditioned and will show a long time course if subjects are reexposed to aversive stimulation. However, it is difficult to see how an analgesic explanation could be used to account for the present results, obtained in testing that involved agonistic responses that were made in the home colony in the absence of aversive stimulation. Although it could be argued that colony fighting might be a painful experience, the alpha animals in this study were very rarely bitten. Furthermore, if they had been bitten and had experienced an analgesic reaction, one would think that the AY rats might show an increase in sustained aggression, since their pain thresholds would supposedly be increased.

Another explanation that does not appear to account for the present results is Weiss's stress-motordeficit hypothesis. Weiss, Glazer, and Pohorecky (1976) have argued that central norepinephrine levels decrease following inescapable shock and that this depletion reduces the rat's ability to mediate movement. However, as noted previously by Maier and Seligman (1976), Weiss's procedure involves many more shock presentations of a much higher intensity than those employed in this study and in most of the published learned helplessness experiments. Furthermore, Weiss's findings consistently indicate that such neurochemical and accompanying activity deficits have a time course of only a few hours. The decrement in alpha aggression found in the present study clearly exceeded this period, with only a minimal recovery in aggression being observed $98 \mathrm{~h}$ after exposure to inescapable shock.

An alternative position that could conceivably account for the present findings is Anisman's reformulation of Weiss's neurochemical depletion hypothesis. In tests with mice (Anisman, de Catanzaro, \& Remington, 1978; Anisman, Irwin, \& Sklar, 1979; Anisman, Remington, \& Sklar, 1979), exposure to stress produced increased synthesis and utilization of norepinephrine and possibly dopamine. Furthermore, if effective coping responses were not available (e.g., inescapable shock), then amine utilization increased to the point at which it exceeded the rate of synthesis and thus led to a net amine depletion. This depletion in turn was shown to be associated with deficits in escape response maintenance when such responses required sustained activity but not when they could be performed rapidly (Anisman et al., 1978). As in Weiss's research with rats, Anisman and his colleagues reported that these stress-induced neurochemical changes were relatively transient. However, often the behavioral effects of inescapable shock have been shown to be fairly long lasting (Anisman et al., 1978; Glazer \& Weiss, 1976a, 1976b; Maier \& Seligman, 1976). In order to account for this apparent paradox without resorting to a learned inactivity or helplessness position, Anisman and Sklar (1979) have shown that reexposure to only a few shocks reinstates the neurochemical depletion and disruption of response maintenance. These authors also state specifically that, following traumatic stress, subsequent presentation of a similar stressor might readily provoke increased amine utilization that would produce a chemical depletion. With regard to the results of the present experiment, exposure to the stress of confronting intruders in the test situation may have been functionally similar enough to the stress produced by prior inescapable shock that amine utilization increased, which, in turn, resulted in a net neurochemical depletion. Since this type of reinstatement process relies on neurochemical changes, as opposed to the learning of competing behaviors during inescapable shock, it is in a good position to account for the long-term reductions in aggression found in the nonshock colony setting. Furthermore, if one assumes that defensive responses are performed more rapidly and involve less sustained effort than aggressive responses, then it is not surprising that they should occur more than aggressive behaviors when previously shocked rats are forced to interact with a strange intruder in their home colonies.

In conclusion, exposure to inescapable shock 
affects a wide variety of behaviors, including subsequent aggressive and defensive responses observed in a nonshock colony situation. The present results revealed that inescapable shock given to an alpha rat radically influenced its aggressive and defensive behaviors and differentially affected the responses of its nondominant colony partner. Obviously, it is important to learn more about the nature of these complex, interacting effects. For example, we are currently investigating the long-term influence of inescapable shock on other behaviors in the colony and whether or not these effects can be prevented or reversed by behavioral and pharmacological treatments.

\section{REFERENCES}

Anderson, D. C., Crowell, C. R., Cunningham, C. L., \& Lupo, J. V. Behavior during shock exposure as a determinant of subsequent interference with shuttle box escape-avoidance learning in the rat. Journal of Experimental Psychology: Animal Behavior Processes, 1979, 5, 243-257.

Anderson, D. C., Croweld, C. R., Wikoff, M. B., \& Lupo, J. V. Activity during prior shock determines subsequent shockelicited fighting in the rat. Animal Learning \& Behavior, 1980, 8, 664-672.

Anisman, H., de Catanzaro, D., \& Remington, G. Escape performance following exposure to inescapable shock: Deficits in motor response maintenance. Journal of Experimental Psychology: Animal Behavior Processes, 1978, 4, 197-218.

Anisman, H., Irwin, J., \& SkLaR, L. S. Deficits of escape performance following catecholamine depletion: Implications for behavioral deficits induced by uncontrollable stress. Psychopharmacology, 1979, 64, 163-170.

Anisman, H., Remington, G., \& Sklar, L. S. Effects of inescapable shock on subsequent escape performance: Catecholaminergic and cholinergic mediation of response initiation and maintenance. Psychopharmacology, 1979, 61, 107-124.

Anisman, H., \& Sklar, L. S. Catecholamine depletion in mice upon reexposure to stress: Mediation of the escape deficits produced by inescapable shock. Journal of Comparative and Physiological Psychology, 1979, 93, 610-635.

Anisman, H., Suissa, A., \& Sxlar, L. S. Escape deficits induced by uncontrollable stress: Antagonism by dopamine and norepinephrine agonists. Behavioral and Neural Biology, 1980, 28, 34-47.

Barn, G. A., Grbmons, J. L., \& Moyer, K. E. The relationship between mouse killing and intraspecific fighting in the albino rat. Behavioral Biology, 1975, 14, 201-208.

Blanchard, D. C., Blanchard, R. J., Takahashi, L. K., \& Takahashi, T. Septal lesions and aggressive behavior. Behavioral Biology, 1977, 21, 157-161.

Blanchard, R. J., \& Blanchard, D. C. Aggressive behavior in the rat. Behavioral Biology, 1977, 21, 197-224.

Blanchard, R. J., Blanchand, D. C., \& Takahashi, L. K. Pain and aggression in the rat. Behavioral Biology, 1978, 23, 291-305.

Blanchard, R. J., Takahashi, L. K., \& Blanchard, D. C. The development of intruder attack in colonies of laboratory rats. Animal Learning \& Behavior, 1977, 5, 365-369.

Bracewelt, R. J., \& Black, A. H. The effects of restraint and noncontingent preshock on subsequent escape learning in the rat. Learning and Motivation, 1974, 5, 53-69.

Costanzo, D. J., Enloe, L. J., \& Hothersali, D. Effects of septal lesions on social dominance in rats. Behavioral Biology, $1977,20,454-462$

Glaze R, H. I., \& WEIss, J. M. Long-term and transitory inter- ference effects. Journal of Experimental Psychology: Animal Behavior Processes, 1976, 2, 191-201. (a)

Glazer, H. I., \& WEIss, J. M. Long-term interference effect: An alternative to "learned helplessness." Journal of Experimental Psychology: Animal Behavior Processes, 1976, 2, 202213. (b)

Grossman, S. P. Aggression, avoidance, and reaction to novel environments in female rats with ventromedial hypothalamic lesions. Journal of Comparative and Physiological Psychology, 1972, 78, 274-283.

Jackson, R. L., Maier, S. F., \& Coon, D. J. Long-term analgesic effects of inescapable shock and learned helplessness. Science, 1979, 206, 91-93.

Maclennan, J. A., Jackson, R. L., \& Maier, S. F. Conditioned analgesia in the rat. Bulletin of the Psychonomic Society, $1980,15,387-390$.

Maier, S. F., Albin, R. W., \& Testa, T. J. Failure to learn to escape in rats previousiy exposed to inescapable shock depends on nature of escape response. Journal of Comparative and Physiological Psychology, 1973, 85, 581-592.

Maier, S. F., Anderson, C., \& Lieberman, D. A. Influences of control of shock on subsequent shock-elicited aggression. Journal of Comparative and Physiological Psychology, 1972, 81, 94-100.

Maier, S. F., Coon, D. J., McDaniel, M. A., Jackson, R. L., \& GRAU, J. The time course of learned helplessness, inactivity, and nociceptive deficits in rats. Learning and Motivation, 1979, $10,467-487$.

MAIER, S. F., \& Jackson, R. L. The nature of the initial coping response and the learned helplessness effect. Animal Learning \& Behavior, 1977, 5, 407-414.

Maier, S. F., \& Seligman, M. E. P. Learned helplessness: Theory and evidence. Journal of Experimental Psychology: General, 1976, 105, 3-46.

Miczex, K. A., \& BARRY, H., III. $\Delta^{9}$-Tetrahydrocannabinol and aggressive behavior in rats. Behavioral Biology, 1974, 11, 261267.

Overmier, J. B., \& Seligman, M. E. P. Effects of inescapable shock on subsequent escape and avoidance learning. Journal of Comparative and Physiological Psychology, 1967, 63, 28-33.

Payne, R., Anderson, D. C., \& Murcunio, J. Preshock-produced alternations in pain-elicited aggression. Journal of Comparative and Physiological Psychology, 1970, 71, 258-266.

Powell, D. A., \& Creer, T. L. Interaction of developmental and environmental variables in shock-elicited aggression. Journal of Comparative and Physiological Psychology, 1969, 69, 219-225.

RAPA port, P. M., \& Maier, S. F. Inescapable shock and foodcompetition dominance in rats. Animal Learning \& Behavior, $1978,6,160-165$.

Roseldini, R. A. Inescapable shock interferes with the acquisition of an appetitive operant. Animal Learning \& Behavior, $1978,6,155-159$.

Skrar, L. S., \& Anisman, H. Stress and cancer. Psychological Bulletin, 1981, 89, 369-406.

Takahashi, L. K., \& Blanchard, R. J. Shock and defensive fighting in the rat. Bulletin of the Psychonomic Society, 1978, 12, 211-213.

Weiss, J. M., Glazer, H. I., \& Pohorecky, L. A. Coping behavior and neurochemical changes: An alternative explanation for the original "learned helplessness" experiments. In G. Serban \& A. Kling (Eds.), Animal models in human psychobiology. New York: Plenum Press, 1976.

Williams, J. L., \& Maier, S. F. Transituational immunization and therapy of learned helplessness in the rat. Journal of Experimental Psychology: Animal Behavior Processes, 1977, 3, 240253.

(Manuscript received August 24, 1981; revision accepted for publication March 23, 1982.) 